\title{
MulHeres EMPREENDEDORAS: O DESAFIO DA ESCOLHA DO EMPREENDEDORISMO E O EXERCÍCIO DO PODER
}

\author{
Eva G. Jonathan*
}

\section{RESUMO}

Este trabalho pretende fazer uma reflexão sobre a relação das mulheres com o poder. Isto é feito embasado em uma síntese de observações realizadas em diferentes estudos sobre o empreendedorismo feminino. Tendo em vista o desafio da escolha do empreendedorismo, analisa-se as motivações das mulheres para empreender, as consequências e as dificuldades enfrentadas, além das estratégias utilizadas para lidar com as demandas vinculadas à multiplicidade dos papéis femininos. O exame das características de liderança, observadas em empreendedoras, revela que elas tendem a construir redes sociais e a exercer o poder com os outros e não sobre os outros. Além disso, no comando de seus empreendimentos sociais, evidencia-se que as mulheres exercem o poder em prol de mulheres, objetivando empoderá-las e promover sua inclusão profissional e social. Com isto, provocam significativas mudanças sociais, econômicas e culturais.

Palavras-chave: empreendedorismo feminino; gênero; poder; empoderamento; empreendedoras sociais; mudança social.

\section{Abstract}

WOMEN ENTREPRENEURS: THE CHALLENGE OF CHOOSING ENTREPRENEURSHIP AND THE EXERCISE OF POWER

This article aims to think about women's relationship to power, based a synthesis of observations made in different studies on women's entrepreneurship. In view of the challenge of choosing entrepreneurship, analyses are performed on women's motivations to become entrepreneurs, on the consequences of this choice, as well as on the difficulties faced by women entrepreneurs and the strategies they use to cope with different demands linked to the multiplicity of gender roles. The examination of leadership characteristics of women entrepreneurs reveals that they tend

* Pontifícia Universidade Católica do Rio de Janeiro, PUC-Rio. 
to build social networks and to use their power with others and not over others. Furthermore, it becomes evident that women social entrepreneurs in charge of their social ventures, while exercising their power on behalf of women, aim to empower them and promote their social and professional inclusion thus causing significant social, economical and cultural changes.

Keywords: women's entrepreneurship; gender and power; empowerment; women social entrepreneurs; social change.

\section{INTRODUÇÃo}

Face à indagação de Freud ("Afinal, o que querem as mulheres?"), busco sintetizar observaçôes oriundas de diferentes estudos realizados com mulheres empreendedoras entre 2000 e 2010 (Jonathan, 2003a; Jonathan, 2003b; Jonathan, 2005; Jonathan, Gomes, Weissheimer, \& Brito, 2005; Jonathan \& Silva, 2007). Através desta síntese, o objetivo deste artigo é refletir sobre a relação das mulheres com o poder, focalizando desafios e consequências do empreendedorismo feminino, bem como as características do poder exercido por mulheres no comando de seus empreendimentos.

Situado no âmbito do trabalho, empreender remete a um processo de identificar oportunidades e gerar algo inovador sob condiçôes de incerteza, assumindo os riscos aí envolvidos (Hisrich \& Peters, 2002). Persistência e visão de futuro estão presentes neste processo que resulta na criação de um empreendimento novo ou de uma nova forma de realizar um trabalho. Em pauta, a inovação de um produto, serviço ou atividade que agregue valor ao que já existe e promova benefícios materiais e/ou sociais.

O empreendedorismo social envolve empreendimentos sem fins lucrativos que visem beneficiar a coletividade. De acordo com Dees (2001), os empreendedores sociais são agentes de mudança que possuem a missão social de proteger e empoderar as pessoas em situação de risco social. Esses empreendedores inovadores perseguem incansavelmente suas novas ideias e visões para melhorar a vida das pessoas (Bornstein, 2007).

Por sua vez, o empreendedorismo feminino é abordado por pesquisadores, como Moore e Buttner (1997), que examinam diversas características psicológicas e sociais das empreendedoras. A presente análise da experiência de mulheres empreendedoras brasileiras com o poder se orienta por um conceito amplo de empreendedorismo, referido tanto à criação quanto à condução de um empreendimento próprio.

Do ponto de vista psicossocial, as empreendedoras inovam, pois ao criarem ou assumirem a liderança de seus próprios empreendimentos transpõem o denomi- 
nado teto de vidro, um obstáculo simbólico que dificulta a ascensão das mulheres a altos níveis da administração empresarial (Morrison, White, \& Van Velsor, 1987). As empreendedoras também promovem inovação na cultura organizacional brasileira. Elas se constituem como um contraponto à exclusão do gênero feminino no processo sucessório de empresas (Macêdo, Caixeta, Guimarães, Macedo, \& Hernandez, 2004).

A crescente participação das mulheres no empreendedorismo brasileiro indica o grande potencial econômico e a significativa contribuição do empreendedorismo feminino para o desenvolvimento do país. Neste sentido, cumpre observar que, de acordo com a última pesquisa publicada pelo Global Entrepreneurship Monitor (GEM) em 2009, pela primeira vez o contingente de mulheres empreendedoras brasileiras (53\%) superou numericamente o de empreendedores homens (47\%), tanto no empreendedorismo por oportunidade quanto no empreendedorismo por necessidade. Ademais, levando em conta o gênero feminino, o Brasil se sagrou como o terceiro país mais empreendedor do mundo, sendo só superado pela Guatemala, onde a presença feminina foi de $54 \%$, e pelo Tonga, onde as mulheres representaram 61\% dos empreendedores (GEM, 2009).

Mas, "afinal, o que querem as mulheres?". Considerando que o empreendedorismo envolve o desafio de escolher criar e/ou conduzir um empreendimento próprio, a indagação acima sugere buscar compreender os fatores que motivam as mulheres a serem empreendedoras e analisar as dificuldades e consequências desta escolha.

Segundo Anderson e Woodcock (1996), os motivos das empreendedoras para empreender são: sobrevivência, insatisfação com a liderança masculina, descoberta de um nicho de mercado, satisfação em fazer as próprias decisões, percepção do desafio que, em combinação com o prazer e o contentamento aí associados, constitui o fator principal.

Por outro lado, as mulheres deixam seus empregos formais para criar suas empresas devido a três fatores, ordenados pelo seu grau de importância: 1) autodeterminação, autonomia e liberdade; 2) desafios e atrações do empreendedorismo, envolvendo aspectos como reconhecimento e oportunidade de estar no controle do seu destino; 3) obstáculos ao desenvolvimento dentro das corporaçōes, envolvendo descompasso com a cultura corporativa, discriminação e barreiras ao desenvolvimento profissional (Moore \& Buttner, 1997). De forma complementar e diferente do que ocorre com os homens, a flexibilidade de horário bem como razões familiares são apontadas como motivos que impulsionam mulheres empreendedoras a desejarem ser seus próprios patrôes (Boden Jr., 1999). 
Em relação às consequências do empreendedorismo, verifica-se que donas de negócios próprios apresentam maiores índices de satisfação do que as executivas. De acordo com Korn/Ferry (2001), as principais fontes desta satisfação diferenciada das empreendedoras remetem ao ritmo de trabalho, à quantidade mínima de interferência de terceiros e aos interesses pessoais satisfeitos. Pode-se argumentar, então, que a satisfação das empreendedoras se deve ao fato de poder atuar com autonomia e ter poder de decisão, fatores importantes na satisfação de mulheres em posição de liderança e que predizem o bem-estar psicológico de mulheres casadas, como mostram Possati e Dias (2002).

Faz parte da vida das mulheres contemporâneas sua ativa participação nos cuidados da família e na administração da casa, bem como seu forte envolvimento em atividades produtivas fora do lar. Porém ainda prevalecem dois estereótipos em relação às mães que trabalham, ora percebidas como pouco competentes e calorosas, não merecendo oportunidades de emprego, promoção ou educação adicional, ora vistas como competentes e frias (Cuddy, Fiske, \& Glick, 2004). Assim, a representação social da maternidade se constitui como uma muralha, dificultando o trânsito das mulheres no espaço público.

A questão requer um exame dos efeitos da multiplicidade de papéis exercidos pelas mulheres nas próprias mulheres. Segundo Jablonski (1996) e Rocha-Coutinho (2003), a denominada dupla jornada, que diz respeito a um acúmulo de tarefas - públicas e privadas -, gera conflitos, problemas e estresse nas mulheres. É necessário reconhecer, porém, que a multiplicidade de papéis femininos não envolve demandas incompatíveis em sua natureza, pois papéis de gênero são construídos socialmente. Cabe, portanto, aos processos de socialização a demarcação de espaços, expectativas e atividades a serem desempenhadas pelos membros da sociedade. A percepção do inconciliável ("ou isso ou aquilo") e o discurso da culpa feminina, internalizada pelas mulheres em sua socialização, emergem no contexto da construção social do sujeito. Nesta perspectiva, a mulher contemporânea ou é culpada por trabalhar ou é culpada por deixar de fazê-lo para se dedicar ao lar e à família.

Face à construção social dos papéis de gênero, pode-se argumentar que, sob certas condições, a multiplicidade de papéis, envolvendo o público e o privado, é vivenciada como algo enriquecedor, sem contradição e estresse. Neste sentido, Cherlin (2001) e Vandewater, Ostrove e Stewart (1997) mostram que mulheres - especificamente mães - trabalhadoras possuem graus mais elevados de bem-estar e estão mais satisfeitas do que aquelas que não trabalham. Assim, uma vida cheia de ocupações, contemplando trabalho e maternagem, proporciona satisfação e sentimento de realização (Cherlin, 2001). Portanto, transitar simultaneamente nos espaços público e privado tem consequências positivas (Tiedge, 2004) e pode ser gratificante e não um fardo, um fator de desgastes e de culpa. 
Importa, pois, compreender de que forma as mulheres lidam com a multiplicidade de papéis além de quais estratégias utilizam para articular demandas vinculadas ao exercício de diferentes papéis. Tiedge (2004) verifica que mães que trabalham tendem a utilizar cinco estratégias para lidar com as demandas do trabalho e da maternagem: i) estratégia supermulher, na qual se busca eficiência no desempenho de todos os papéis sociais; ii) planejamento e administração do tempo, estratégia cuja meta é otimizar o desempenho dos papéis; iii) reinterpretação cognitiva das demandas, que envolve, por exemplo, a diminuição de seu próprio padrão de exigências; iv) afastamento das atividades menos importantes, podendo envolver não assumir novas responsabilidades; v) estratégia multitarefa, que implica em desempenhar várias atividades ao mesmo tempo.

Por sua vez, executivas cariocas de classe média possuem o ideal de conciliar necessidades familiares, profissionais e pessoais, adotando estratégias tais como: não levar trabalho para casa garantir um tempo pessoal, harmonizar os compromissos de todos os familiares, garantindo um tempo de convivência, delegar tarefas a todos os familiares, estabelecendo parcerias na condução da casa (Rocha-Coutinho, 2003).

A análise de como as mulheres contemporâneas lidam com a multiplicidade de papéis sugere a relevância que conferem ao ato de fazer escolhas sem pressóes ou cobranças. Uma necessidade a ser reconhecida pela sociedade como um todo.

Ao ressaltar as características da liderança feminina, Brush (1998) argumenta que as empreendedoras tendem a adotar uma forma singular de manejar com diferentes recursos organizacionais. Admite-se que existem aspectos recorrentes e tendências no exercício do poder feminino nos seus empreendimentos, mesmo sem defender um modelo feminino de empreendedorismo (Hisrich, Brush, Good, \& DeSouza, 1997).

No contexto brasileiro, segundo Machado (2002), o comportamento gerencial feminino se caracteriza por: i) ter objetivos definidos e amplos, entre eles segurança e satisfação no trabalho, satisfação dos clientes, ética do cuidar e responsabilidade social; ii) manter as estruturas organizacionais simples, informais, horizontais e descentralizadas, dando ênfase à cooperação, à integração e aos relacionamentos interpessoais; iii) adotar estratégias inovadoras em busca de qualidade e da satisfação de todos os envolvidos; iv) empregar muitas mulheres; v) exercer uma liderança interativa e cooperativa, facilitando a adoção de um processo decisório participativo.

Ademais, em estudos sobre empreendedorismo social, Najafizadeh e Mennerick (2003) e Oppedisano (2004) enfatizam que a liderança das empreendedoras se volta para atividades usualmente associadas à imagem tradicional das mulheres: 
seu altruísmo, compaixão e preocupação com os outros. Possivelmente, esta é uma imagem estereotipada. Sem encontrar estudos específicos realizados no contexto brasileiro, a intenção aqui é explorar a temática das empreendedoras sociais no exercício do poder a partir de dados por mim coletados recentemente e que aqui serão parcial e resumidamente expostos.

\section{CONSIDERAÇÕES METOdológicas}

Neste trabalho, descrevo brevemente os aspectos metodológicos compartilhados nas diferentes pesquisas realizadas. Com exceção do recente estudo no contexto do empreendedorismo social, realizado ao longo dos anos de 2009 e 2010 e cujos dados ainda não foram publicados, o detalhamento da metodologia de cada estudo pode ser encontrado em Jonathan (2003a), Jonathan (2003b), Jonathan (2005), Jonathan et al. (2005) e Jonathan e Silva (2007).

A estruturação da abordagem metodológica comum a todos os estudos realizados foi norteada pelo objetivo de expor a compreensão que as próprias mulheres possuíam de suas experiências como empreendedoras. Buscou-se descrever o universo simbólico das empreendedoras sem realizar comparações entre mulheres e homens.

Participaram do estudo 149 empreendedoras do Rio de Janeiro, sendo que 116 possuíam empreendimentos em segmentos variados da economia, 16 eram empreendedoras de alta tecnologia (Tecnologia de Informação e Biotecnologia) e 17 eram líderes de empreendimentos sociais sem fins lucrativos. Entre estas últimas aproximadamente a metade mantinha empreendimentos com projetos específicos para mulheres, uma característica analisada nos resultados apresentados mais adiante.

Em um primeiro contato feito pessoalmente, por telefone ou por $e$-mail, as participantes foram convidadas a participar de uma pesquisa sobre a sua experiência como empreendedora brasileira. No encontro agendado, elas receberam informações sobre os objetivos e os procedimentos da pesquisa, firmando sua concordância em participar do estudo (Termo de Consentimento Livre e Esclarecido). Preencheram, então, um questionário com dados descritivos pessoais e organizacionais. Em seguida, foram realizadas entrevistas semiestruturadas com a duração de aproximadamente 45 minutos.

Dentre os diversos temas tratados nas entrevistas realizadas, o presente trabalho enfoca: i) a motivação das mulheres para empreender; ii) as consequências dessa es- 
colha; iii) as dificuldades enfrentadas pelas empreendedoras; iv) as características do exercício da liderança feminina em empreendimentos com e sem fins lucrativos.

As entrevistas foram gravadas com o consentimento das participantes. As mesmas foram transcritas. Visando apreender a produção de sentido das empreendedoras contida em seus discursos, as transcriçōes foram submetidas a uma análise de conteúdo (Bardin, 1970). Esta metodologia envolveu um exame transversal (entre as participantes) bem como um exame vertical (de cada participante) dos depoimentos. Na próxima seção, apresento o material recorrente que emergiu e foi organizado em categorias dentro de cada um dos temas focalizados, sendo, então, ilustrado com falas das empreendedoras.

\section{Resultados}

Inicialmente são organizados os dados que compõem o perfil das empreendedoras. Em seguida, dispostos ao longo de dois eixos, são apresentados os dados obtidos na análise das entrevistas. O primeiro destes eixos diz respeito ao desafio enfrentado por mulheres que escolhem o empreendedorismo como forma de se inserir na esfera pública do trabalho. O segundo remete às características na forma de conduzir seus empreendimentos.

\section{CARACTERIZAÇÃO DO PERFIL}

\section{SOBRE AS EMPREENDEDORAS E SEUS EMPREENDIMENTOS}

O perfil pessoal das empreendedoras que emerge é o de mulher madura (média em torno dos 45 anos), altamente escolarizada (a maioria com nível superior completo), casada (em sua maioria), com filhos (em média, dois filhos) e ativamente ocupada com a condução de seus empreendimentos, aos quais dedica cerca de 10 horas diárias.

Apesar de contemplar uma grande diversidade, os empreendimentos com fins lucrativos comandados por mulheres tendem a se constituir como microempresas, com menos de 10 funcionários. A presença mais marcante encontra-se no setor de serviços e, secundariamente, no setor de comércio.

Em relação aos empreendimentos sociais, estes, embora tendam a apresentar a estruturação básica de uma microempresa, se configuram frequentemente de forma mais ampla ao incorporarem o trabalho de voluntários. Tais empreendi- 
mentos atuam em áreas muito diversificadas, sendo expressiva sua presença no segmento de desenvolvimento econômico/geração de renda, bem como no setor de participação cidadã/direitos humanos.

\section{PRIMEIRO EIXO}

\section{SOBRE O DESAFIO DE ESCOLHER O EMPREENDEDORISMO}

Tendo em foco relatos de mulheres que optam por se inserir no mercado de trabalho através da criação/condução de seus próprios empreendimentos, abaixo estão os dados relativos às seguintes questões: i) motivação das mulheres para empreender; ii) consequências dessa opção; iii) dificuldades enfrentadas pelas empreendedoras.

i) Motivação - Dentre variados fatores motivacionais e incentivadores, o motivo mais frequentemente invocado pelas mulheres para empreender é a busca de autorrealização. Com uma postura proativa, as empreendedoras almejam atualizar seu potencial pessoal e profissional. O empreendimento próprio emerge como algo desafiador, prazeroso, no qual podem imprimir seus próprios valores e formas de ser/agir e que permite exercer sua capacidade de decisão. Abaixo, a questão é ilustrada com as falas, seguidas de indicação da idade da empreendedora e de sua área de atuação:

“[...] Eu sempre tive vontade de fazer algo maior, ter maior participação na estratégia, maior controle no que eu estava realmente fazendo no meu trabalho [...]” (30, serviços).

“[...] Eu não queria mais trabalhar para ninguém, eu queria ter um negocinho que fosse pequenininho, mas que fosse meu, que tivesse [...] o meu jeito, que eu tava cansada de receber ordens [...]" (43, serviços).

Outro expressivo motivo para ser empreendedora é a busca de independência e/ou estabilidade financeira. Como nos dizem as empreendedoras, elas ativamente buscam uma maior autonomia financeira e uma melhoria das condições de vida:

“[...] a vontade de ser independente, nunca gostei de depender de ninguém [...] não queria depender de ninguém e casada não me sentia bem dependendo do marido, o que é pior ainda [...]" (37, indústria). 
"[...] o que me motivou foi poder ajudar financeiramente o meu marido nas contas da casa, por isso eu quis fazer tudo certinho, dentro da lei [...]” (52, indústria).

Por outro lado, mudanças na vida privada ou profissional das empreendedoras podem impulsioná-las a criar/assumir seus próprios empreendimentos. A escolha do empreendedorismo como forma de inserção no mercado de trabalho se configura, então, como uma reação a eventos que no espaço privado remetem à separação conjugal, à mudança de cidade e, como ilustrado a seguir, aos filhos e à idade atingida:

"[...] cuidava dos filhos, até que as crianças crescem e você quer fazer alguma coisa. Então, resolvi abrir o meu próprio negócio né, em vez de procurar emprego [...]" (50, comércio).

"Quando saí da empresa [...] eu estava em uma faixa etária que era considerada velha [...], então, eu tive que abrir o meu próprio negócio, porque ninguém aceita uma mulher com quarenta e poucos anos [...]” (56, comércio).

No espaço profissional, estar fora do mercado de trabalho, o desemprego e a aposentadoria são os principais eventos que deflagram a opção das mulheres pelo empreendedorismo:

"[...] fiquei completamente fora do mercado de trabalho, porque me formei [...], não fiz nada [...], fiquei desesperada [...]” (42, comércio).

“[...] já tinha uma aposentadoria que já me segurava [...], pude fazer uma coisa que eu sempre quis que é trabalhar por conta própria [...]” (63, indústria).

ii) Consequências - Os dados indicam que a experiência de ser empreendedora acarreta, principalmente, uma vivência de bem-estar subjetivo, sendo intensos os sentimentos de satisfação pessoal e de autorrealização experimentados. $\mathrm{O}$ exercício de criatividade, a liberdade de ação, a identificação com aquilo que faz, as conquistas diárias, entre outros aspectos, alimentam tais sentimentos e promovem autoestima, contribuindo para a construção de uma autoimagem de vencedora. Os depoimentos abaixo ilustram tais questôes:

“[...] estou me realizando profissionalmente [...], fazendo alguma coisa para o meu futuro [...]; a consequência é um prazer imenso [...], meu trabalho tem sido reconhecido” (34, indústria).

"Eu gosto de fazer realizar minhas ideias com liberdade de expressão [...], ter uma independência é fundamental para quem tem vontade de criar no trabalho" (36, comércio). 
“[...] considero que a gente tem vencido várias etapas e vem construindo; não acho que sou uma vencedora, acabei e pronto; fico satisfeita com as coisas que a gente consegue $[. .$.$] " (30, serviços).$

Outro efeito de ser empreendedora remete à percepção que as empreendedoras têm de que são levadas a assumir múltiplas responsabilidades. Neste contexto, elas percebem certos desgastes e custos, tais como ter pouco tempo para si e para a família, possuir uma pesada carga horária de trabalho e ter o lazer prejudicado. No entanto, ênfase maior é dada aos benefícios do envolvimento e da atuação em diversas áreas, destacando-se o orgulho pelas realizaçôes, o respeito próprio, as conquistas diárias no trabalho, além da boa relação com filhos, familiares, funcionários e outros parceiros do trabalho. A seguir, analisam-se mais detalhadamente as dificuldades enfrentadas pelas empreendedoras.

iii) Dificuldades - Diversos obstáculos ao empreendedorismo no Brasil são, reiteradamente, mencionados: os altos custos e a burocracia para regulamentar e formalizar um empreendimento; as dificuldades para acessar crédito e serviços financeiros; os altos impostos (Schlemm, 2007). Para além destes obstáculos, enfatizo duas questões apontadas como dificuldades enfrentadas pelas mulheres: as barreiras impostas pela discriminação e os empecilhos associados à dupla/tripla jornada.

Os resultados mostram que as empreendedoras têm pouca vivência de barreiras devido ao gênero. No entanto, quando há tal vivência, a discriminação emerge como algo superado. É o que se depreende da fala abaixo:

"[...] precisei me impor para que eles pudessem acreditar e depois eles ficam macios. A discriminação foi mais no início" (55, serviços).

Em relação às múltiplas e potencialmente conflitantes demandas - profissionais, familiares e pessoais - com as quais as empreendedoras se defrontam, no que se convencionou chamar de dupla ou tripla demanda, observa-se que elas se sentem desafiadas. Apresentam, então, uma busca proativa e assertiva pelo equilíbrio, pela harmonia entre as diferentes dimensôes do seu espaço vital. Como nos diz uma empreendedora:

"[...] tempo a gente faz; a gente tem que ter tempo para poder fazer de tudo [...]" (47, comércio e serviços). 
Embora reconheçam dificuldades, o discurso das empreendedoras enfatiza as conquistas, a conciliação do isso com aquilo, revelando pouco ou nenhum lugar para remorso e culpa, ao mesmo tempo que criam a imagem de ser vitoriosa, como apontado anteriormente. $\mathrm{O}$ depoimento abaixo ilustra a questão:

"Eu acho que me considero uma vencedora porque em tudo, eu acho que em tudo, eu consigo conciliar a minha vida, o meu marido, a vida com meus filhos, a minha vaidade, as minhas atividades pessoais. Eu me considero uma vencedora porque eu acho que eu estou conseguindo vencer obstáculos. Eu estou conseguindo escutar as críticas com ouvido bom. Eu acho que o equilíbrio é uma vitória [...]" (34, indústria).

Os dados sugerem que as empreendedoras superam as contradições inerentes às diferentes demandas, transformando a ordem social e a si mesmas. Observa-se que elas tendem a utilizar, principalmente, três estratégias de ação para enfrentar os triplos desafios: i) auto-organização do tempo; ii) estabelecimento de parcerias e cumplicidade; iii) utilização de dispositivos de alívio de tensão.

Utilizando sua capacidade de administrar, as empreendedoras buscam planejar e organizar bem o tempo de que dispõem, alternando o foco de sua atenção ou separando os espaços das diferentes atividades, como ilustram as falas a seguir:

"Eu acordo bem cedo, levo meu filho menor na escola e vou para a ginástica; depois começo no telefone e à tarde venho para a empresa. Daqui busco o do meio no futebol e volto para casa [...] Concilio tudo, tem que dar para conciliar" (37, comércio).

"[...] dentro do salăo, eu me dedico ao salão, aos clientes, às pessoas, aos funcionários [...]; quando estou na minha casa, [...] eu vivo a minha família e esqueço daqui (empresa) [...]" (40, serviços).

Outra estratégia utilizada pelas empreendedoras para enfrentar demandas conflitantes é estabelecer alianças com familiares e sócios. Neste sentido, elas nos dizem:

"[...] meu marido é muito parceiro [...], se ele tiver que fazer um arroz, ele vai fazer [...]; a gente é muito unido [...]" (47, comércio e serviços).

"[...] eu até consigo conciliar bem [...]; a gente é sócia; a gente divide, então, uma sempre cobrindo a outra [...]" (34, serviços).

A terceira estratégia utilizada no enfrentamento de múltiplas solicitações remete a expedientes que diminuem a tensão tais como: realizar atividades físicas, 
fazer viagens; cultivar a espiritualidade; fazer psicoterapia. Como afirma uma das empreendedoras:

"[...] procuro equilibrar tudo [...] sou uma pessoa feliz com tudo, mas existem momentos que dá vontade de desistir; [...] eu gosto de viajar; viajo com meu marido ou até sozinha [...] tem que ter momentos de escape [...]” (34, serviços).

SEGUNDO EIXO

\section{SOBRE O EXERCÍ́CIO DO PODER PELAS EMPREENDEDORAS}

A partir de agora, a atenção se dirige para a forma de as empreendedoras exercerem o poder. Duas questôes norteiam a apresentação dos resultados das pesquisas: (i) as características de liderança no empreendedorismo feminino; (ii) o empoderamento de mulheres e as mudanças sociais observadas no empreendedorismo social feminino.

(i) Características de liderança no empreendedorismo feminino - Fortemente comprometidas com seus empreendimentos, as mulheres empreendedoras revelam paixão e otimismo no exercício da liderança. Os dados indicam que a condição feminina tende a ser valorizada pelas empreendedoras. Assim, por um lado, as empreendedoras relatam que é forte a presença de mulheres trabalhando nos seus empreendimentos; por outro, verifica-se que as empreendedoras atribuem relevância a sua forma feminina de trabalhar e liderar:

"Tenho uma forma feminina de conduzir a empresa e isso acaba funcionando muito bem" (36, serviços).

É interessante observar que as empreendedoras se dedicam a construir uma malha de bons relacionamentos internos e externos, sendo a atividade de tecer redes sociais um aspecto central de sua forma de exercer a liderança. Apoiadas em relações amistosas, calorosas, embora respeitosas e profissionais com os funcionários, as empreendedoras exercem uma liderança interativa, caracterizada por pouca ou nenhuma hierarquia e por sensibilidade às demandas e sugestões dos funcionários, com quem mantêm diálogos abertos, pautados em transparência de informação, ética, sinceridade, confiança e cooperação. As falas abaixo ilustram a liderança apoiada em redes sociais constituídas de parcerias internas e externas:

"[...] a gente sempre trabalhou juntinho [...] tem uma hierarquia 100\% ho- 
rizontal [...] todo mundo entra na minha sala e eu ouço todo mundo e me ouvem; um esquema de franqueza total [...]; o tom da empresa é o diálogo, ética, transparência [...]” (36, serviços).

“[...] a gente está sempre buscando algum tipo de parceria que possa torná-la maior e até porque foi assim que ela cresceu [...] o fato é que meus clientes são meus atuais fornecedores, meus ex-funcionários são meus atuais clientes [...] a empresa criou essa sinergia [...]" (45, serviços).

Dessa forma, fica evidente que a liderança das empreendedoras se caracteriza por ser o exercício do poder com os outros e não do poder sobre os outros.

Por fim, analisam-se os resultados observados no exercício do poder de mulheres que possuem empreendimentos sociais com programas orientados para mulheres (fato observado em aproximadamente metade das empreendedoras sociais participantes da pesquisa realizada em 2009/2010).

(ii) Empoderamento de mulheres e mudanças sociais no empreendedorismo social feminino. No presente estudo, o termo empoderamento remete à obtenção de informações que favoreçam a reflexão e tomada de consciência quanto à condição atual em que a pessoa se encontra. Promovendo, com isso, a ativa formulação de mudanças capazes de libertá-la da dependência na qual se encontra (Schiavo \& Moreira, 2005). Neste sentido, os resultados mostram que as empreendedoras sociais empoderam a população feminina alvo dos projetos de seus empreendimentos tanto por lhe proporcionar amplo apoio emocional quanto por promover mais diretamente sua inclusão social e profissional.

O empoderamento promovido pelas empreendedoras sociais, através do apoio emocional, é mediado por mecanismos de conscientização, fortalecimento da identidade social e resgate/incremento da autoestima, respectivamente ilustrados abaixo:

"[...] estar sempre tendo que dizer da importância de se autoafirmar [...] até despertar essa consciência em mulheres que não despertaram, que não têm ainda essa consciência [...] se fortalecer pra poder melhorar o próprio status dela [...] porque ela tem que criar o próprio espaço [...]” (41, cultura e gênero).

"[...] compartilhar experiências lhes dá um sentido de identidade, de relacionamento com outras mulheres, [...] lhes dá visibilidade" (30, desenvolvimento econômico/geração de renda). 
"[...] trabalhar a questão da autoestima é o primeiro passo [...] para elas acreditarem que realmente podem fazer alguma coisa (trabalho gerador de renda) [...] possam estar montando a sua própria história, né?" (35, desenvolvimento econômico/geração de renda, educação e participação cidadã/direitos humanos).

Por outro lado, as empreendedoras sociais empoderam mulheres ao promover mais diretamente sua inclusão social e profissional. Algumas iniciativas contemplam a assistência legal e a proteção de direitos, fortalecendo-as enquanto cidadãs. Outras envolvem dar assistência técnica, de modo a fomentar o desenvolvimento de conhecimentos e habilidades profissionais. Neste caso, variados cursos, oficinas e treinamentos estimulam mulheres a explorar recursos que viabilizem, de forma sustentada, novas oportunidades de trabalho. Há clara intenção de empoderamento no seguinte depoimento:

“[...] não é nem o ensinar a pescar [...], mas o gerenciar (da renda); [...] colocar a pessoa para pensar estrategicamente de que aprendendo a pescar ela vai conseguir gerar renda pra ela” (38, desenvolvimento econômico/geração de renda).

É interessante observar que as empreendedoras sociais tendem a desempenhar um papel de modelo para outras mulheres, estimulando, através de aprendizagem direta e vicária, a criação de amplas redes de mulheres profissionais. Há, portanto, um "efeito dominó", uma vez que empoderar mulheres leva ao empoderamento de outras mulheres, em uma crescente espiral de inclusão social.

Por fim, depreende-se do discurso das empreendedoras sociais que desenvolvem projetos voltados para mulheres que elas buscam promover amplas transformações sociais.

Por um lado, verifica-se a intenção de contribuir para o desenvolvimento ou o fortalecimento de políticas públicas que favoreçam as mulheres e lhes proporcione uma melhor qualidade de vida. Como nos diz uma empreendedora:

"Eu luto por mudanças nas políticas públicas, por conscientização da sociedade de que precisamos de justiça social [...]” (53, serviços/geração de renda).

Por outro lado, empreendedoras sociais provocam mudança social, ao atuarem na promoção de uma maior equidade na sociedade. Assim, por vezes, desenvolvem em mulheres habilidades e potencial para exercer mais influência nos âmbitos profissional, econômico e social; alternativamente, apoiam financeiramente outros projetos sociais mantidos por mulheres e voltados para a promoção dos direitos das mulheres. A fala abaixo ilustra a questão: 
"[...] começar a criar a consciência que empoderar mulheres significa promover mudanças sociais [...] Os fundos das mulheres têm que existir para que os direitos das mulheres continuem existindo porque se as mulheres não têm recursos é muito difícil que possam lutar pelos direitos delas [...]" (52, desenvolvimento econômico, educação, participação cidadā, entre outras áreas).

Uma última questão suscita análise e remete à mudança social decorrente da multiplicação dos benefícios sociais provocados por empreendimentos sociais voltados para mulheres. Os resultados indicam que as empreendedoras sociais têm a intenção de transformar a sociedade pela multiplicação dos benefícios concedidos às mulheres que participam dos projetos desenvolvidos para elas. É o que ilustra o seguinte depoimento:

"[...] você tem cada vez mais mulheres como chefes de família e se estas mulheres têm educação, acesso à moradia, etc, etc, você vai ter mais crianças na escola, mais crianças tendo um atendimento escolar mais alto. [...] o melhor investimento social que se pode fazer para desenvolver um país é nas mulheres [...]" (52, desenvolvimento econômico, educação, participação cidadã, ...).

\section{Discussão}

À luz dos dados obtidos, verifica-se que o perfil pessoal das empreendedoras, bem como o perfil de seus empreendimentos voltados para a obtenção de lucro, se assemelha aos observados em outros estudos sobre o empreendedorismo feminino no Brasil (Machado, Barros, \& Palhano, 2003). Por sua vez, as empreendedoras sociais também compartilham com as demais empreendedoras as características de alta escolaridade, idade madura, a condição de ser casada e ter filhos, em sua maioria, e o profundo comprometimento com seus empreendimentos, aos quais dedicam muitas horas diárias. Já a constatação da marcante presença dos empreendimentos sociais brasileiros comandados por mulheres nas áreas de desenvolvimento econômico/geração de renda e de participação cidadã/direitos humanos sugere uma quebra da visão estereotipada de que no empreendedorismo social feminino a atividade das mulheres é orientada por compaixão e altruísmo (Najafizadeh \& Mennerick, 2003; Oppedisano, 2004).

$\mathrm{O}$ conjunto de fatores que motivam as mulheres a serem empreendedoras se caracteriza por complexidade e variedade. Com uma atitude proativa, as empreendedoras buscam realizar seu potencial profissional e pessoal e o empreendimento próprio as desafia a imprimir seus próprios valores e formas de agir e a exercer sua 
capacidade de decisão. Dentre os principais motivos que fundamentam a opção das mulheres pelo empreendedorismo destacam-se: a busca de autorrealização e a busca de independência e/ou estabilidade financeira. Revela-se, assim, que o quadro motivacional que impulsiona as mulheres brasileiras a criarem/conduzirem seus próprios empreendimentos encontra respaldo nos estudos realizados com empreendedoras de outras culturas (Anderson \& Coodcock, 1996; Moore \& Buttner, 1997).

É necessário compreender, também, que as mulheres, por vezes, optam pela criação de um empreendimento próprio em resposta a mudanças significativas que ocorrem nos espaços privado e/ou público. Ademais, questôes familiares podem fundamentar a opção das mulheres pelo empreendedorismo, na medida em que percebem o empreendimento próprio como capaz de viabilizar esquemas mais flexíveis de trabalho (Boden Jr., 1999).

Embora as empreendedoras reconheçam certos custos e desgastes, tais como uma pesada carga de trabalho que lhes deixa pouco tempo para cuidar da família e de si e afeta seu lazer, o exercício do empreendedorismo resulta, predominantemente, em bem-estar subjetivo nas mulheres. Neste sentido, são enfatizados a imensa satisfação pessoal e o sentimento de autorrealização, levando as empreendedoras a construírem uma autoimagem de vencedoras. Como empreendedoras, possuem maior liberdade de ação e possibilidade de satisfazer interesses pessoais (Korn/Ferry, 2001), assim como maior autonomia e poder de decisão (Possati \& Dias, 2002), circunstâncias que causam prazer e elevam a autoestima.

Por outro lado, ao se analisarem as dificuldades enfrentadas pelas empreendedoras, verifica-se que é escassa a vivência de discriminação devido ao gênero ou, alternativamente, que esta vem referida como algo superado. Os dados sugerem que está em andamento a desconstrução da discriminação de gênero - processo com o qual contribuem as próprias mulheres. Em relação à denominada muralha da maternidade, que discrimina mulheres-mães com base no duplo estereótipo - se competente no trabalho, pouco calorosa, e vice-versa (Cuddy, Fiske, \& Glick, 2004) -, busca-se uma maior compreensão sobre o tema, discutindo a questão dos múltiplos papéis e responsabilidades.

De forma geral, chama a atenção o prazer expresso pelas empreendedoras em relação a seu envolvimento em atividades nos espaços público e privado, bem como o orgulho e respeito próprio que acompanham as diárias conquistas pessoais, profissionais e no âmbito familiar. Os altos índices de satisfação e bem-estar encontrados entre as empreendedoras, dentre as quais muitas são mães, vem ao encontro dos dados encontrados entre mulheres-mães que trabalham quando comparadas com as que não trabalham (Cherlin, 2001; Vandewater, Ostrove, \& 
Stewart, 1997). Enfatizam-se, assim, as consequências positivas decorrentes de uma dupla atuação nos domínios público e privado (Tiedge, 2004).

Dessa forma, embora as empreendedoras não neguem problemas e dificuldades associadas à multiplicidade de papéis desempenhados (Jablonski, 1996; RochaCoutinho, 2003), elas se sentem desafiadas, buscam ativamente o equilíbrio entre as necessidades familiares, profissionais e pessoais (Rocha-Coutinho, 2003). Face aos obstáculos, tendem a se ver como vitoriosas, deixando pouco ou nenhum espaço para remorso ou culpa. O conjunto dos dados sugere que se enfatize a expressão duplo/triplo desafio em substituição à dupla/tripla jornada, pois esta última remete a um acúmulo de tarefas, associadas aos espaços público e privado, pensadas como um fardo e, supostamente, inconciliáveis em sua natureza.

Para enfrentar o triplo desafio - envolvendo questões profissionais, familiares e pessoais -, as empreendedoras utilizam, principalmente, três conjuntos de estratégias: i) auto-organização do tempo, envolvendo planejar/administrar o tempo disponível, alternar ou priorizar o foco de atenção e separar os espaços das atividades; ii) estabelecimento de parcerias e cumplicidade, envolvendo alianças com familiares, sócios, funcionários; iii) dispositivos de alívio de tensão, envolvendo atividade física, viagens, espiritualidade e psicoterapia. É interessante observar que tais estratégias, de um modo geral, se assemelham tanto às descritas por Tiedge (2004), em seu estudo com mães americanas que trabalham, quanto às observadas por Rocha-Coutinho (2003) em suas pesquisas com executivas brasileiras. Quando comparadas com as executivas, as empreendedoras demonstram singularidade no uso de estratégias para lidar com demandas múltiplas ao estabelecerem parcerias com sócios e funcionários e, ainda, transmitirem aos colaboradores internos a relevância de se dar atenção às questões pessoais. Evidencia-se, assim, que as empreendedoras superam as contradições das diferentes demandas transformando a si mesmas e a ordem social.

Em relação às características do exercício do poder, verifica-se que na condução de seus empreendimentos, estruturados com pouca hierarquia, as empreendedoras tendem a exercer uma liderança compartilhada com seus funcionários, mantendo com eles diálogos francos, transparentes e cooperativos, aspectos também observados no comportamento gerencial feminino (Machado, 2002). Ademais, apoiadas em sólidas parcerias internas e externas, as empreendedoras tornam a atividade de construir redes sociais um fator central em sua forma de liderar (Moore \& Buttner, 1997). Sem necessariamente rotular o conjunto de características acima descritas de modelo feminino de empreender (Hisrich et al., 1997), pode-se reconhecer que a liderança das empreendedoras se caracteriza como um poder com os outros 
e, não, sobre os outros. Em pauta, uma organização singular dos recursos organizacionais (Brush, 1998).

No âmbito do empreendedorismo social, observa-se que, entre as empreendedoras, a missão de empoderar pessoas em desvantagem e risco social (Dees, 2001) é frequentemente voltada para a população feminina. Neste sentido, as empreendedoras exercem seu poder no intuito de fortalecer outras mulheres, promovendo condições que permitam que estas, de forma ativa, superem a situação de desvantagem social na qual se encontram (Schiavo \& Moreira, 2005). Foram observadas duas estratégias de empoderamento utilizadas pelas empreendedoras junto à população feminina: i) proporcionar amplo apoio emocional através da conscientização, do fortalecimento da identidade social e do resgate/incremento da autoestima; ii) atuar no sentido de viabilizar a inclusão social e profissional, fornecendo assistência legal às mulheres, promovendo o incremento de seus conhecimentos e habilidades e motivando-as a buscar novas oportunidades de inserção no mercado de trabalho. Em sua missão de empoderar, as empreendedoras demonstram enorme persistência, colocando sua energia, paixão, ideias e visões a serviço da melhoria da qualidade de vida das mulheres (Bornstein, 2007).

Promover uma profunda mudança econômica e social emerge como principal objetivo das empreendedoras sociais com projetos voltados para mulheres. Tal transformação é favorecida não só pelo empoderamento de mulheres, que resulta numa espiral de inclusão social e em maior equidade social do ponto de vista do gênero, mas também pela contribuição dada por estas empreendedoras ao estabelecimento de políticas públicas em prol das mulheres. Sobretudo, ao desenvolverem projetos voltados para mulheres, as empreendedoras sociais multiplicam os benefícios sociais, uma vez que crianças e toda a família serão beneficiadas. $\mathrm{O}$ empreendedorismo social feminino demonstra, assim, seu imenso potencial para promover uma progressiva transformação no sistema social e econômico (Najafizadeh \& Mennerick, 2003).

\section{CONSIDERAÇÕES FINAIS}

A articulação entre observações realizadas em diferentes estudos sobre o empreendedorismo feminino possibilita uma rica reflexão sobre a relação das mulheres com o poder. A escolha do empreendedorismo feita pelas mulheres como forma de se inserir no mercado de trabalho vem ao encontro de uma busca proativa de autorrealização e de independência/estabilidade financeira, respondendo, por vezes, também, às mudanças significativas que ocorrem no seu espaço privado ou profissional. 
O exercício do empreendedorismo proporciona intenso prazer e sentimentos de satisfação e bem-estar subjetivo nas empreendedoras, dando pouco espaço a arrependimentos. Conclui-se que a escolha do empreendedorismo coloca um desafio para as mulheres e seu enfrentamento resulta numa conquista. Elas desejam atualizar o seu potencial pessoal e profissional, almejam transitar com equilíbrio nos espaços público e privado e, para isso, utilizam estratégias que harmonizem as demandas pessoais, familiares e profissionais. Nesta trajetória, as empreendedoras promovem espaços de transformação de si mesmas e do contexto socioeconômicocultural no qual se inserem.

No entanto, é necessário argumentar que a responsabilidade pelo equilíbrio entre o público e o privado, pela reconfiguração destes espaços, não deve ser unicamente das mulheres. Cabe à sociedade encontrar novas alternativas para articular mais adequadamente o mundo do trabalho e a realidade da vida familiar contemporânea em benefício de homens, mulheres e crianças. Certamente, as mulheres querem isso!

Na condução dos seus empreendimentos, as empreendedoras exercem uma liderança compartilhada, baseada em parcerias internas e externas, sendo central a atividade de construção de redes sociais. Dessa forma, evidencia-se que, ao invés de exercerem o poder sobre os outros, as empreendedoras exercem o poder com os outros.

Dessa forma, as empreendedoras sociais, com projetos voltados para mulheres, exercem o poder em prol das mulheres, empoderando-as, através do apoio emocional e da promoção de sua inclusão social e profissional. Os benefícios sociais se multiplicam, uma vez que as mulheres ainda são as maiores responsáveis por cuidar da família e muitas são também as principais responsáveis por sua manutenção. Portanto, o exercício do poder por empreendedoras sociais tem potencial para promover amplas transformações sociais, econômicas e culturais. Parafraseando o depoimento de uma empreendedora social, pode-se bem resumir a questão: o melhor investimento para transformar a sociedade é investir nas mulheres. Penso que, afinal, as mulheres assinariam tal mote!

\section{REFERÊNCIAS}

Anderson, A. H., \& Woodcock, P. (1996). Effective entrepreneurship: a skills and activity based approach. Oxford, UK/Cambridge, MA: Blackwell Publishers Ltd.

Bardin, L. (1970). Análise de conteúdo. Lisboa: Edições 70.

Boden Jr., R. J. (1999). Flexible working hours, family responsibilities and female employment: gender differences in self-employment selection. The American Journal of Economics and Sociology, 58 (1), 71-83. 
Bornstein, D. (2007). How to change the world: social entrepreneurs and the power of new ideas (Updated edition). New York: Oxford University Press.

Brush, C. G. (1998). A resource perspective on women's entrepreneurship: research, relevance and recognition. Proceedings of the organization for economic cooperation and development conference on women entrepreneurs in small and medium-sized enterprises. Paris, France.

Cherlin, A. J. (2001). Public and private families: an introduction (3 ${ }^{\text {rd }}$ ed.). New York: McGraw Hill.

Cuddy, A. J. C., Fiske, S. T., \& Glick, P. (2004). When professionals become mothers, warmth doesn't cut ice. Journal of Social Issues, 60 (4), 701-718.

Dees, J. G. (2001). The meaning of "social entrepreneurship". Retirado de <http://www. caseatduke.org/documents/dees_sedef.pdf>.

Global Entrepreneurship Monitor-GEM (2009). Relatório Global de Empreendedorismo no Brasil. Retirado de <http://repositorio.aev.edu.br/files/01a403a0cf823d0b10716205acd4.pdfs.

Hisrich, R. D., Brush, C. G., Good, D., \& DeSouza, G. D. (1997). Performance in entrepreneurial ventures: does gender matter? Frontiers of Entrepreneurial Research. Wellesley, MA: Center for Entrepreneurial Studies, Babson College. Retirado de <http://www. babson.edu/entrep/fer/papers97/sum97/hisb.htm>.

Hisrich, R. D., \& Peters, M. P. (2002). Entrepreneurship (5 ${ }^{\text {th }}$ ed.). Boston: Irwin/McGraw Hill.

Jablonski, B. (1996). Papéis conjugais: conflito e transição. Relação amorosa, casamento, separação e terapia de casal, Coletâneas da ANPEPP, 113-123.

Jonathan, E. G. (2003a). Empreendedorismo feminino no setor tecnológico brasileiro: dificuldades e tendências. In: Anais do III EGEPE - Encontro de Empreendedorismo e Gestão de Pequenas Empresas, pp. 41-53. Brasília.

Jonathan, E. G. (2003b). Facing success and work-family challenges in Brazil: the case of women business owners. In: M. Stasiak (Ed.). Values in an era of transformation (pp. 275-287). Lodz: Wyzsza Szkola Humanistyczno-Economiczna w Lodzi.

Jonathan, E. G. (2005). Mulheres empreendedoras: medos, conquistas e qualidade de vida. Psicologia em Estudo, Maringá, 10 (3), 373-382.

Jonathan, E. G., Gomes, J. L., Weissheimer, J. C., \& Brito, M. R. (2005). Mulheres empreendedoras no Brasil: motivaçôes e conseqüências. [Resumo] Em União Latino-americana de Entidades de Psicologia (org.). I Congresso Latino-americano de Psicologia-ULAPSI (União Latino-americana de Entidades de Psicologia). São Paulo.

Jonathan, E. G., \& Silva, T. M. R. (2007). Empreendedorismo feminino: tecendo a trama de demandas conflitantes. Psicologia \& Sociedade, 19 (1), 77-84.

Korn/Ferry International. (2001). What women want in business: a survey of executives and entrepreneurs. Retirado de <http://www.kornferryinstitute.com/files/pdf1/What_Women_Want_in_Business1.pdf>. 
Macêdo, K. B., Caixeta, C. M. M., Guimarães, D. C., Macedo, G. N. S., \& Hernandez, J. C. (2004). O processo sucessório em organizações familiares e a exclusão da mulher. Psicologia \& Sociedade, 16 (3), 69-81.

Machado, H. V. (2002). Identidade empreendedora de mulheres no Paraná. (Tese de Doutorado). Programa de Pós-Graduação em Engenharia de Produção. Universidade Federal de Santa Catarina.

Machado, H. V., Barros, G. V., \& Palhano, D. Y. M. (2003). Conhecendo a empreendedora norte-paranaense: perfil, porte das empresas e dificuldades de gerenciamento. In: Anais do III EGEPE - Encontro de Empreendedorismo e Gestão de Pequenas Empresas, pp. 171-197. Brasilia/DF.

Moore, D. P., \& Buttner, E. H. (1997). Women entrepreneurs: moving beyond the glass ceiling. Thousand Oaks, CA: Sage Publications.

Morrison, A., White, R., \& Van Velsor, E. (1987). Breaking the glass ceiling: can women reach the top of America's largest corporations? Reading, MA: Addison-Wesley.

Najafizadeh, M., \& Mennerick, L. A. (2003). Gender and social entrepreneurship in societies in transition: the case of Azerbaijan. Journal of Third World Studies, Fall. Retirado de <http://findarticles.com/p/articles/mi_qa3821/is_200310/ai_n9337811/>.

Possati, I. C., \& Dias M. R. (2002). Multiplicidade de papéis da mulher e seus efeitos para o bem-estar psicológico. Psicologia Reflexão e Crítica, 15 (2), 293-301.

Oppedisano, J. (2004). Giving back: women's entrepreneurial philanthropy, Women In Management Review, 19 (3), 174-177. Retirado de <http://www.emeraldinsight.com/ journals.htm?articleid=1412299\&show=pdf>.

Rocha-Coutinho, M. L. (2003). Quando o executivo é uma dama: a mulher, a carreira e as relaçôes familiares. In: Féres-Carneiro, T. (org.). Família e casal: arranjos e demandas contemporâneas (pp. 57-77). Rio de Janeiro: Editora PUC-Rio/Loyola.

Schiavo, M. R., \& Moreira, E. N. (2005). Glossário social. Rio de Janeiro: Comunicarte.

Schlemm, M. M. (2007). Empreendedorismo no Brasil. Instituto Brasileiro de Qualidade e Produtividade do Paraná.

Tiedge, L. B. (2004). Processes of change in work/home incompatibilities: employed mothers 1986-1999. Journal of Social Issues, 60 (4), 787-800.

Vandewater, E. A., Ostrove, J. M., \&. Stewart, A. J (1997). Predicting women's well being in midlife: the importance of personality development and social role involvements. Journal of Personality and Social Psychology, 72 (5), 1147-1160.

Aceito para publicação em 28 de outubro de 2010 